\title{
Três romances intersticiais
}

Maurício Silva*

A nossa chamada belle époque, período que no Brasil correspondeu às duas primeiras décadas do século XX, foi época fértil em produçōes literárias ecléticas e, às vezes, originais. Ainda que desconsiderarmos os estertores de algumas tendências literárias já em franco declínio no último quartel do século anterior, o cenário cultural da época revela-se bastante heterogêneo e intenso, ao contrário de algumas posições críticas que insistem em imaginar esta quadra de nossa história literária como um período intervalar e inexpressivo. ${ }^{1}$

Mas sob essa diversidade latente, esconde-se uma homogeneidade estética subreptícia que acaba conferindo à época uma característica de flagrante dicotomia, a qual parece se desdobrar infinitamente: as duas primeiras décadas do século trazem, do ponto de vista literário, a marca do embate entre unidade e diversidade culturais, ao mesmo tempo em que - no que se refere à sua pretensa unidade - assistimos ao desenvolvimento de duas tendências estéticas aparentemente opostas: uma retrógrada, academicista, conservadora e visceralmente ligada aos cânones literários de um passado nào muito remoto; outra progressista, inovadora, mais afeita à problematizaçào social dos motivos estéticos. Assim, se a primeira pode ser representada por figuras expressivas, mas excessivamente formalistas, do cenário cultural da época, como Coelho Neto, Afrânio Peixoto, João do Rio, Benjamim Costallat, Humberto de Campos e outros, a segunda é caracterizada por nomes não menos expressivos, embora fadados a uma posição que, via de regra, beira à marginalidade deliberada ou compulsória, como Lima Barreto, Euclides da Cunha, Graça Aranha ou Augusto dos Anjos. ${ }^{2}$

*Prof. Dr. de Literatura Brasileira da Universidade de Santo Amaro (SP)

1. É o caso, por exemplo, de SODRÉ, Nelson Werneck. O Naturalismo no Brasil. Rio de Janeiro, Civilização Brasileira, 1965. Tal posição é condenada por FARIA, Gentil Luiz de. A Presença de Oscar Wilde na "Belle Époque" Brasileira. São Paulo, Pazzartz, 1988; e NEEDELL, Jeffrey D. Belle Époque Tropical. Sociedade e Cultura de Elite no Rio de Janeiro na Virada do Século. São Paulo, Companhia das Letras, 1993.

2. Para uma visão sucinta do cenário cultural da época, consultar BOSI, Alfredo. O PréModernismo. São Paulo, Cultrix, 1969; BROCA, Brito. A Vida Literária no Brasil. 1900. Rio de Janeiro, José Olympio, 1960; M. ACHADO NETO, A. L. Estrutura Social da Repriblica das Letras (Sociologia da V ida Intelectual Brasileira. 1870-1930). São Paulo, Grijalbo/Edusp, 1973; MIGUELPEREIRA, Lúcia. Prosa de Ficiào. De 1870 a 1920. Rio de Janeiro, José Olympio, 1950; SÜSSEKIND, Flora. Cinematógrafo de Letras, Literatura, Técnica e Modernizaçào no Brasil. São Paulo, Companhia das Letras, 1987; e VENTURA, Roberto. Estilo Tropical, História Cultural e Polemicas L iterárias no Brasil. 1870-1914. São Paulo, Cia. das Letras, 1991. 
Nào obstante essa duplicidade aparentemente rígida, algumas obras e autores escapavam a qualquer uma das tendências em que se possa dividir o período: tratase de obras que se colocam nos interstícios deixados pelos grandes blocos estéticos, que se revelam caudatários e herdeiros de uma ou outra tendência, mas que já apontam para inovaçōes e recursos ainda nào completamente assimilados (às vezes, porém, completamente renegados) pelos principais autores em vigência. Nào são, como estas observações preliminares podem sugerir, obras absolutamente inovadoras e originais: ao contrário, na maior parte dos casos, sào produçòes singulares de autores que ainda estào em busca de um caminho, que criaram obras circunstanciais ou que pervagam, indecisos, por todas as tendências estéticas sem se aterem em nenhuma. Pode-se mesmo dizer que se trata de obras menores, mas que, no contexto tenso e inflexível de nossa Belle Époque, destacam-se como achados estéticos insólitos, resguardando para si o direito de optar por um certo liberalismo artístico e, por isso mesmo, produzindo romances descompromissadas com estéticas prevalentes e dominantes. Obras, enfim, que muitas vezes não encontram espaço (ou encontram-no reduzidamente) nas nossas historiografias literárias, mas que, sem dúvida alguma, contribuíram, de um lado, para o alargamento das possibilidades estéticas verificadas na época e, de outro lado, para a consolidaçào no período de um certo ecletismo literário que nào deixa de ser salutar ao próprio desenvolvimento da literatura nacional. ${ }^{3}$

Em meio a uma variedade intensa de obras intersticiais, pelo menos três romances destacam-se pela sua originalidade e versatilidade literárias: Mocidade Morta (1900) de Gonzaga Duque, Exaltação (1916) de Albertina Bertha e Madame Pommery (1920) de Hilário Tácito. Três obras que, cronologicamente, mostram-se bem situadas, ocupando o início, o meio e o fim da nossa Belle Époque literária e consolidando, talvez, uma terceira tendência estética, a par das duas já sugeridas há pouco: a estética do insólito, do improvável, da libertação artística. Mas também, três romances que deixaram suas marcas no período por uma originalidade algo permissiva, pessoalíssima, a despeito da sua limitada amplitude literária. Como se afirmou, nào participaram do fausto literário promovido pelos autores oficiais sob os auspícios da recém-fundada Academia Brasileira de Letras, nem adensaram as lides

3. Para a consideração do periodo como eclético, consultar LIMLA, Alceu Amoroso. Primeiros Estudos I. Contribuicia à História do Modernismo Literário. O Pré-modernismo de 1919 a 1920. Rio de Janeiro, Agir, 1948; e GÓES, Fernando. "Notícia sobre a Poesia Pré-Modernista". Panorama da Poesia Brasileira. O Pré-Modernismo. Rio de Janeiro, Civilização Brasileira, 1960, Vol. V, p. XXIXILI. 
insubordinadas dos chamados pré-modernos. Ao contrário, optaram antes pela via da criaçào descompromissada com qualquer premissa estética vigente, pelo abrandamento das tendências literárias, pelo deliberado meio-tom artístico.

Talvez estes romances sejam a única expressão verdadeiramente intervalar no bom e no mal sentido - do período em questão.

\section{Romance de libertação}

O melhor exemplo do que afirmamos acima pode ser encontrado na figura singular do escritor e crítico de arte Gonzaga Duque. Tendo colaborado em diversos periódicos, como crítico e cronista mundano, Gonzaga Duque foi também fundador de revistas literárias importantes, além de ocupar postos públicos de relevo. ${ }^{\dagger}$ Como crítico, exercitou a defesa incondicional dos autores simbolistas, na literatura, e dos jovens artistas contra a realismo burguês, nas artes plásticas. ${ }^{5}$ Publicou, além de uma parca obra ficcional, livros de crônica e crítica de artes, tornando-se o nosso primeiro crítico de artes plásticas especializado."

Mas seu grande mérito parece ter sido, ainda, escrever um dos romances mais originais das primeiras décadas do presente século, o que de certo modo, e apesar das conjeturas acimas expostas, lhe confere uma posiçào de destaque no cenário artístico nacional, particularmente dentro do movimento simbolista. Já nào se pode negar, atualmente, a importância que o movimento simbolista teve na história da arte mundial e, em particular, na literatura. Tendo gerado grandes artistas, cujo renome espalhou-se por todos os recantos por onde a cultura ocidental conheceu acolhimento, o Simbolismo logrou dar à expressào literária uma perspectiva totalmente nova, bem diferente da estética parnasiana que vigorava inconteste na época de seu aparecimento. Certo, nào foi sempre assim: desprezado pela maioria dos críticos e artistas, seu início foi marcado por

4. Para a atuação de Gonzaga Duque como jornalista e colaborador de revistas literárias e mundanas, consultar DIMAS, Antônio. Tempos Euföricos. Análise da Revista Kosmos: 1904-1909. Sào Paulo, Ática, 1983.

5. Cf. HELD, Maria Sílvia Barros de. "Gonzaga Duque: Alguns Aspectos de sua Crítica de Arte". Comnnicarte, Pontificia Universidade Católica de Campinas, Campinas, Vol. 05, No. 09/ 10: 90-100, 1987; e C.tST.ANONON, Júlio. "Gonzaga Duque: Ficção e Crítica de Artes Plásticas". In: C.ARV.ALHO, José Murilo de et Alii. Sobre o Pré-Modernismo. Rio de Janeiro, Fundação Casa de Rui Barbosa, 1988, p. 83-103.

6. Cf. MURICI, Andrade. Panorama do Movimento Simbolista Brasileiro. Rio de Janeiro, Imprensa Nacional, 1952; e BOSI, Alfredo. História Concisa da L iteratura Brasileira. São Paulo, Cultrix, 1977. 7. Para sua importância como autor simbolista, consultar MOISÉS, Massaud. História da Literatura Brasileira. Simbolismo. São Paulo, Cultrix/Edusp, 1984. 
infinitas controvérsias, mas sobretudo por críticas acerbas contra suas propostas estéticas. É neste contexto, por exemplo, que um intelectual ecumênico do porte de Anatole France considerava o movimento simbolista uma doença, opinião que não era muito diferente entre os mais conceituados críticos brasileiros, como um José Veríssimo. ${ }^{8}$

De qualquer maneira, apesar das críticas e dos ataques, o Simbolismo vingou e deu origem a verdadeiras obras-primas. No Brasil, embora a poesia simbolista tenha sobrepujado a prosa, foi possível observar o aparecimento de alguns romances de primeira linha, entre eles a insuperável obra de Gonzaga Duque, Mocidade Morta (1900). Embora a crítica o consagre como um dos principais romances simbolistas nacionais, Mocidade Morta destaca-se do cenário artístico brasileiro por uma certa independência estética, afurmando-se antes como um romance intervalar, que encontra melhor posicionamento entre diversas tendências literárias do começo do século. Tem como tema central a batalha travada entre a arte acadêmica e a arte nova, a primeira representada pelos medalhões da pintura clássica e a segunda, pelos jovens insubmissos. Pode ser visto, por isso mesmo, como um romance de fundo histórico, esmerando-se, por exemplo, em retratar a boemia artística da época."

$\mathrm{Na}$ verdade, tal embate parece ser o cenário propício para se discutir o pungente problema da libertaçào artística, tema caro ao seu autor, um dos nossos mais atentos críticos de arte. Em poucas palavras, trata-se de uma defesa obstinada da liberdade, simbolizada pela pintura à plein air dos impressionistas. É comovente verificar, neste contexto, as tentativas do autor de valorizar aspectos libertários da arte, como a valorizaçào essencial da paisagem, nào mais considerada como acessório frívolo da pintura, o que ia completamente contra os pressupostos estéticos acadêmicos:

O academicismo nos impòe suas formas, nào é? Desprezemo-lo e desprezemo-las. Costas à Academia! E vamos fazer em nossa oficina o contrário do que é letra dos seus códices, do que é dogma dos seus cânones, porque faremos novo e bom, vivo e forte! Foi assim, meu amigo, que a paisagem se libertou da parte acessorial dos quadros, surgiu vitoriosa da geometria dos sombrios processos oficiais. ${ }^{10}$

8. SUFFEL, Jacques. Anatole France par lui-même. Paris, Seuil, s.d.; e VERÍSSIMO, José. Que é Literatura? e Outros Escriptos. Rio de Janeiro, Garnier, 1907.

9. Cf. EULÁLIO, Alexandre. "Sobre Mocidade Morta". In: CARVALHO, José Murilo de et Alii. Sobre o Pré-Modernismo, p. 183-188; e MLACHADO NETO, A. L. Estrutura Social da Repuiblica das I etras.

10. DUQUE, Gonzaga. Mocidade Morta. Rio de Janeiro, Três, 1973, p. 45. 
Além de revelar todo o sentido libertário da obra de Gonzaga Duque, esta passagem apontar igualmente para a possibilidade da caracterização de seu romance como um livro intersticial, conforme vínhamos sugerindo desde o princípio: afirmase contra o academicismo cultural, ao mesmo tempo em que se mantém ligado a certas regras formais da estética simbolista, sem avançar para rol dos artistas verdadeiramente pré-modernos.

De qualquer maneira, a ânsia pela libertaçào prevalece e acaba envolvendo até mesmo fatos circunstanciais, como o canto de Henriette, livre como o canto de um pássaro; a procura de ateliês livres como locus privilegiado para a criação; ou o espaço livre da janela a desvendar o plano exterior na sua plenitude. A própria linguagem utilizada pelo autor, a despeito de sua dívida para com o Simbolismo, foge do domínio absoluto, quase tirânico, dos cânones estéticos do período: inovadora e sangüínea, revela desde o princípio a busca de novos modos de expressão, como bem percebeu um estudioso do assunto. ${ }^{11}$

Assim, tudo é liberdade nesse autêntico romance da libertação.

Ocorre que até mesmo a liberdade conhece limites, impostos já pela necessidade de reaçào daqueles que se sentem prejudicados pelas suas mudanças, já pela imaturidade da época em que a mesma logra se manifestar. Aos poucos, o clima de libertaçào total entrevista nos primeiros capítulos do romance vai se adensando mais e mais, apontando para um inegável retrocesso. A própria paisagem conhece uma retraçào, fechando-se entre prédios desabitados e praças abandonadas; a atmosfera de fechamento completa-se com a descriçào da casa de Camilo, sombria e acanhada; ou de sua própria existência, reclusa, melancólica, tudo desaguando para uma pungente e irremediável desilusào, para o fim mesmo dos ideais de uma mocidade morta:

Agora, Camilo vai esmoendo o tédio amargo pelos tortuosos escaminhos da reclusào voluntária, fugindo de quem the reanime lembranças, acabrunhado pela insolvabilidade das dividas que contraiu, vexado com a inutilidade em que se arrasta. Toda a energia que em seus recessos encontra ele a emprega nesta obscura luta, singular e íntima, de esforços contra impossíveis, debatendo-se sem apelo na incerteza do destino. ${ }^{12}$

11. KURY, Adriano da Gama. "A Linguagem dos Pré-Modernistas. Alguns Problemas na Fixação dos Textos". In: C.IRT.tLHO, José Murilo de et Alii. Sobre o Pré-Modernismo, p. 205215.

12. DUQUE, Gonzaga. Mocidade Morta, p. 244. 
Já nào é mais a liberdade incondicional, a busca de espaços amplos e abertos, o anseio pela revoluçào libertária que impera, mas uma triste e funda desesperança, como se os jovens idealistas de ontem nào passassem de velhos desiludidos, vencidos por uma vida sem perspectivas.

\section{A filosofia da morbidez}

Ao lado de Gonzaga Duque, Albertina Bertha emerge como uma das mais originais romancistas intersticiais da Belle Époque, sobretudo com um romance que, sem ser um primor em termos de idealizaçào estética, afirma-se como obra de inesperada originalidade: Exaltaçào (1916).

Contrariamente a Gonzaga Duque, liga-se de forma oblíqua ao movimento acadêmico, pelo modo em que o romance é modado, relativamente rígido, forjado por meio de uma linguagem castiça, sem desvios de prosódia ou gramática, com um apurado rigor lingüístico. Isso apesar da densidade poética de sua linguagem, o que faz do romance um dos mais líricos de sua época, levando um romancista e crítico rigoroso a considerá-lo um autêntico poema em prosa. ${ }^{13}$ Em compensaçào, no que se refere aos aspectos conteudísticos da obra, Albertina Bertha procurou inovar em muitos sentidos, abordando, por exemplo, com veemência e coragem, a temática do papel desempenhado pela mulher na sociedade. Chega a colocar sob suspeição o casamento, uma das tradiçòes sociais e familiares mais intocáveis na época, com a ousadia que só encontrariamos - e, mesmo assim, limidatamente numa Júlia Lopes de Almeida ou numa Cármen Dolores. ${ }^{1+}$

Mas sua relevância fica mesmo por conta da filosofia mórbida, decadente, nietzschiana de que Exaltaģão é dotado. Com efeito, recebendo influência direta do pessimismo de Nietzsche, Albertina Bertha esmera-se em fazer de suas personagens seres psicologicamente decadente, marcados por um temperamento nervoso, por uma inteligência mordaz, por uma índole febril. Nesse sentido, sua morbidez tem pouco de enfermiço e corrupto, e muito de um mundanismo blasé. Trata-se, como

13. Cf. B.tRRETO, Lima. Correspondência. São Paulo, Brasiliense, 1956, Tomo I, p. 284. Lima Barreto trata da autora também em B.ARRE'TO, Lima. Impressões de Leitura. São Paulo, Brasiliense, 1956.

14. Sobre a atuação destas duas autoras, no que diz respeito à temática feminina, consultar LOPES, Maria Angélica. "Júlia Lopes de Almeida e o Trabalho Feminino na Burguesia". L _usoBrazilian Review, Wisconsin, Vol. 26, No. 01: 45-57, 1989; e LOPES, Maria Angélica. "O Crime da Galeria Crystal, em 1909: a Jornalista como Árbitro". Travessia, Florianópolis, No. 23: 167-176, 19)1. 
afirma a própria autora, de uma morbidę lirica. Atente-se para uma das descriçòes que esta nos faz da protagonista do romance:

Quanta vez elle the nào surprehendera, em tardes calidas, olhares obliquos, esses olhares que têm o gesto das plantas, dos elementos, das coisas que fogem, olhares que têm integralidade, lucidez ardente, clamor desesperado, gritos silenciosos de um determinismo implacavel (...) E, na sua meninice, a fascinaçào morbida para com as coisas mortas, a volupia funebre que a agitava, ao enterrar os insectos, as bonecas quebradas

ou com que nos brinda a própria protagonista, falando de si mesma:

Adoro a paz, a solidão, as coisas estranhas (...) Rio-me muito, digo tolices; mas tambem tenho melancolias, que me roem as proprias fontes da existencia; é-me um mal ingenito. ${ }^{15}$

De fato, trata-se de uma personalidade incomum, cuja principal característica, talvez, seja uma certa disponibilidade para com uma existência morbígena, introspectiva, afeita a uma espécie de ultra-romantismo decadente. Apesar disso, Exaltą̧ão nào deixa de ser um romance de idéias, nào exatamente de idéias concretas, reais, mas antes abstratamente filosóficas, existenciais, sem chegar a ser existencialistas. Tudo isso, conformado por uma insólita perscrutaçào do eu-profundo, o que faz do romance uma obra que se situa num meio-termo entre o psicologismo bourgetiano de um Coelho Neto e o psicologismo fatalista de um Gonzaga Duque.

Curiosamente, o excessivo psicologismo de que padece o romance, aliado à filosofia mórbida que o conforma, nào foi suficiente para encobrir uma de suas principais virudes: o tratamento animoso dado à temática da libertação feminina. Numa época em que a mulher parecia completamente limitadas nos mais elementares diretos do ser-humano, Albertina Bertha toma as dores da minoria de que fazia parte e acaba colocando sob suspeiçào todos os mais empedernidos preconceitos em relaçào à mulher, vigentes na época. Suas opiniòes, nesse sentido, deveriam soar de modo incômodo aos ouvidos dos guardiòes das tradiçòes sociais masculinas, fazendo de sua obra, às vezes, um verdadeiro libelo em favor dos direitos feministas, ainda que tudo isto estivesse envolto por uma delicada roupagem existencialista, decadente e filosoficamente mórbida.

15. BERTH.A, . Albertina. Evaltaiao. Rio de Janeiro, Jacintho Ribeiro dos Santos, 1918, p. (1) (. \$3 


\section{Um discípulo de Machado}

Um último romance merece a denominação de intersticial, que demos aqui às obras que se colocam entre as tendências vigentes durante as duas primeiras décadas do século, participando de todas, mas não se filiando integralmente a nenhuma delas: trata-se de Madame Pommery (1919), de Hilário Tácito.

Já vai longe o tempo em que Tristào de Ataíde deu a um de seus ensaios, publicados em O Jornal, esse título: um discípulo de Machado." Ali, o eminente crítico falava de um novo romance que aparecia ao público leitor (V'ida e Morte de $M$. J. Gonqaga de Sa) e comparava Lima Barreto a Machado de Assis, encontrando argumentos diversos que corroborasse essa asserção. Hodiernamente, é possível analisar esse problema com um pouco mais de distanciamento e afirmar que ambos os romancistas encontram-se em posiçòes - dentro do complexo universo literário - não exatamente opostas, mas diversas. De qualquer maneira, seu ensaio continua sendo um referencial para o estudo dessa obra de Lima Barreto, e se nào emerge como uma apreciaçào acabada da mesma, possui ao menos o mérito de se tratar de uma crítica corajosa e superiormente realizada no calor da hora, o que por si só já é um grande feito.

Curiosamente, o título dado ao ensaio pelo célebre crítico encaixaria melhor e com muito mais propriedade ao romance de Hilário Tácito. Trata-se de uma obra que procura narrar as aventuras da célebre cafetina Ida Pomerikowski (cognominada Madame Pommery) em Sào Paulo, revelando todo um processo de assimilaçào civilizatória que tinha como referência a cidade de Paris, na virada do século. ${ }^{17}$ Além disso, o romance possui uma peculiaridade nada desprezível: enquadra-se numa tendência particular da expressào literária do começo do século, justamente aquela que revelava uma preocupaçào com aspectos problemáticos da realidade nacional, colocando-o ao lado dos mais eminentes representantes do que já se chamou uma vez de Brasil Real. ${ }^{18}$

Mas o fato mais saliente do livro fica por conta da dívida que o mesmo possui para com a prosa singular de Machado de Assis, fato aliás já percebido e

16. LIMA, Alceu Amoroso. Primeiros Estudos. Contribuição a História do Modernismo Literário. O Pré-Modernismo de 1919-1920.

17. Cf. MORAES, Eliane Robert. "Memória de uma Cafetina". Memória, Departamento de Patrimônio da Eletropaulo, São Paulo, Ano IV, No. 15: 70-77, Jul./Ago. 1992.

18. Cf. BOSI, Alfredo. "As Letras na Primeira República". In: FAUSTO, Boris (dir). História Geral da Civilizacia Brasileira. O Brasil Republicano. Sociedade e Instituiçoes (1889-1930). Rio de lanciro, Difel, 1977, tomo III, Vol. 02, p. 293-319. 
comentado pela crítica. ${ }^{12}$ Com efeito, sào inúmeros os indícios que revelam em Hilário Tácito um caudatário de Machado de Assis, sobretudo no que diz respeito ao estilo literário. Um exemplo claro dessa relaçào pode ser entrevista na utilizaçào de um recurso, pelo autor paulista, muito caro a Machado, a saber: aquela espécie tào singular de se referir ao leitor no decorrer da narraçào, cooptando-o e colocandoo como participante ativo do enredo ficcional. Nào poucas vezes, Hilário Tácito emprega recurso semelhante, dando inclusive às passagens desse tipo o desprendimento e uma ironia semelhante àqueles empregados pelo mestre decimonônico. Atente-se para essa passagem tipicamente machadiana:

Convençam-se todos. Este livro é um livro honesto e de bôa fé. Si eu quizesse, ter-lhe-ia dado aquella epigraphe de Montaigne: C'est icy un livre de bonne foy, lecteur. Nào lh'a dei porque nào quiz, porque embico com as epigraphes e, tambem, porque já esperava, de principio, que havia de fazer mais tarde esta citação; e sou grande inimigo de repetir cousas que já disse. Si, entretanto, o leitor achar nisso conveniencia ou merito, não lhe vedo de a inscrever agora no frontespicio, com a condição que a copiará muito exactamente e sem trocar a ortographia. ${ }^{20}$

Trechos como este repetem-se ao longo de todo o livro, e nào é apenas a referência direta ao leitor, bem ao estilo de Machado, mas sua ironia dissimulada, o convite à participaçào do leitor como contribuinte concreto da obra literária, referências à própria pessoa do autor, etc.

A utilizaçào de alguns recursos gráficos, como preencher algumas linhas por pontos, a exemplo de Sterne, modelo inegável de Machado; as finalizaçòes de capítulos, irônicas, inesperadas, espirituosas, do romancista carioca; algumas tiradas exemplares próprias do grande romancista; tudo isso também está presente nesse típico romance machadiano. Observe-se, ainda uma vez, outro exemplo comum do que aqui se busca afirmar:

Todavia, nem tudo se perde no aranzel precedente. Pois uma conclusào resulta, pelo menos: que é do interesse desta história relembrar-se o aspecto geral da Paulicéa, quando primeiro se

19. GRIECO, Agripino. Evolucião da prosa brasileira. Rio de Janeiro, José Olympio, 1947. 20. TÁCITO, Hilário. Madame Pommery. São Paulo, Revista do Brasil, 1919 , p. 07. 
defrontou com Mme. Pommery.

Neste ponto é natural que a penna me estremeça um pouco, em reticencias symbolicas dos saltos alados com que o meu espirito vae retrocedendo pelos caminhos do tempo, até chegar àquella edade, tão celebrada dos poetas, em que comecei a curtir as nauseas dos primeiros cigarros e as consequencias das primeiras dentadas no fructo prohibido, e quase sempre deteriorado. ${ }^{21}$

Novamente a ironia singular do romancista, fechando o entrecho com uma observaçào sagaz e, ao mesmo tempo, crítica da sociedade da época. Além disso, evidencia-se a semelhança entre os dois autores no que se refere ao especto formal, gráfico, em que a obra é moldada. Nào é necessário transcrevermos outros exemplos para corroborar as afirmaçdes aqui realizadas: eles estão por todo o livro de Hilário Tácito, e nào seria difícil percebê-los nem ao mais superficial leitor de Machado.

Observador lúcido de sua época, possivelmente Hilário Tácito foi também um leitor contumaz de Machado de Assis, romancista que serviu de modelo a mais de um autor secundário. De qualquer modo, Madame Pommery destaca-se do universo dos romances esteticamente inferiores, mas que - isolados - desempenharam papel de revelo nas primeiras décadas do século, como um Mocidade Morta de Gonzaga Duque ou um Exaltação de Albertina Bertha. Além disso, é relevante o caráter documental que, vez por outra, o romance parece assumir quase que deliberadamente, dando-nos um painel entre malicioso e humorístico ${ }^{22}$ dos anos eufóricos que começavam despontar no horizonte. Afirma-se, portanto, como uma obra de auxílio no trabalho de reconsituiçào da nossa Belle Époque, ${ }^{23}$ e, também, como um esboço sigular do mundanismo que, desde o começo do século, tomava conta da sociedade urbana de Sào Paulo e do Rio de Janeiro. ${ }^{24}$

21. T’́CITO, Hilário. Madame Pommery, p. 14.

22. Cf. BARRETO, Lima. "Mme Pommery". Impressões de Leitura, p. 111-117.

23. Sobre algumas características históricas da época em questão, retratadas no romance de Hilário Tácito, consultar SEVCENKO, Nicolau. Orfeu Extático na Metrópole. São Paulo, Sociedade e Cultura nos Frementes Anos 20. São Paulo, Companhia das Letras, 1992; e NEEDELL, Jeffrey D. Belle Époque Tropical. Sociedade e Cultura de Elite no Rio de Janeiro na L irada do Século..

24. Cf. C.ARONE, Edgard. "Madame Pommery Companhia Limitada". Análise e Conjuntura, Belo Horizonte, Vol. 05, No. 02: 15-36, Mai./Ago. 1990; e BRAIT, Beth. "A Cortesã como Educadora do Bom Gosto: um Caso Exemplar na Modernização de São Paulo". Revista da Biblinteia Mário de Andrude, São Paulo, Vol. 53: 67-76, Jan./Dez. 1995. 